\title{
Plant Water Status as an Index of Irrigation Need in Deciduous Fruit Trees
}

Kenneth A. Shackel, H. Ahmadi, W. Biasi, R. Buchner, D. Goldhamer, S. Gurusinghe, J. Hasey, D. Kester, B. Krueger, B. Lampinen, G. McGourty, W. Micke, E. Mitcham, B. Olson, K. Pelletrau, H. Philips, D. Ramos, L. Schwankl, S. Sibbett, R. Snyder, S. Southwick, M. Stevenson, M. Thorpe, $\mathrm{S}$. Weinbaum, and J. Yeager

Additional INDEX WORDs. midday stem water potential, pressure chamber

Summary. To be useful for indicating plant water needs, any measure of plant stress should be closely related to some of the known short- and medium-term plant stress responses, such as stomatal closure and reduced rates of expansive growth. Midday stem water potential has proven to be a useful index of stress in a number of fruit tree species. Day-to-day fluctuations in stem water potential under wellirrigated conditions are well correlated with midday vapor-pressure deficit, and, hence, a nonstressed baseline can be predicted. Measuring stem water potential helped explain the results of a 3-year deficit irrigation study in mature prunes, which showed that deficit irrigation could have either positive or negative impacts on tree productivity, depending on soil conditions. Mild to moderate water stress was economically beneficial. In almond, stem water potential was closely related to overall tree growth as measured by increases in trunk cross-sectional area. In cherry, stem water potential was correlated with leaf stomatal conductance and rates of shoot growth, with shoot growth essentially stopping once stem water potential dropped to between -1.5 to $-1.7 \mathrm{MPa}$. In pear, fruit size and other fruit quality attributes (soluble solids, color) were all closely associated with stem water potential. In many of these field studies, systematic tree-to-tree differences in water status were large enough to obscure irrigation treatment effects. Hence, in the absence of a plant-based measure of water stress, it may be difficult to determine whether the lack of an irrigation treatment effect indicates the lack of a physiological response to plant water status, or rather is due to treatment ineffectiveness in influencing plant water status. These data indicate that stem water potential can be used to quantify stress reliably and guide irrigation decisions on a sitc-specific basis.

The theory that water must experience conditions of tension, as a consequence of its long distance transport in the xylem of plants, is an important component of the current Soil-plantatmosphere continuum (SPAC) model.

Although doubts have been expressed recently concerning the occurrence of any tension in the xylem of plants at all (Canny, 1995), the SPAC model is believed to explain the occurrence of plant water deficits (i.e., plant tissue water potentials that are less than fully saturated), and also to predict how these deficits will increase as soil water becomes less available (e.g., Kramer, 1983).

\footnotetext{
Pomology Department, University of California, Davis, CA, 95616-8683.

This work was supported in part by the Almond Board of California, California Cherry Growers and Industries Foundation, California Pear Advisory Board, California Prune Board, California Cherry Advisory Board, and USDA/NRI CGP 91-37100-6669.

The cost of publishing this paper was defrayed in part by the payment of page charges. Under postal regulations, this paper therefore must be hereby marked advertisement solcly to indicate this fact.
} 
Table 1. California prune orchards surveyed during the 1993 growing season.

\begin{tabular}{llll}
\hline Site & $\begin{array}{l}\text { Location } \\
\text { (county) }\end{array}$ & $\begin{array}{l}\text { Irrigation } \\
\text { system }\end{array}$ & Soil type \\
\hline 1 & Tulare & Drip & Foster fine sandy loam \\
2 & Tulare & Mister & Foster sandy loam \\
3 & Tulare & Mister & Foster sandy loam \\
4 & Yuba & Flood & Valdez silt loam/Ryer loam \\
5 & Yuba & Microjet & Landlow clay/Landlow loam \\
6 & Butte & Drip & Gridley clay loam \\
7 & Glenn & Microjet & Arbuckle gravelly loam \\
8 & Glenn & Flood & Arbuckle gravelly loam \\
9 & Glenn & Solid set sprinkler & Shallow claypan \\
10 & Tehema & Movable sprinkler & Los Robles clay loam \\
11 & Tehema & Movable sprinkler & Los Robles clay loam \\
\hline
\end{tabular}

Physically, as a plant tissue loses water, any reduction in the total water potential of the tissuc must be reflected in a corresponding reduction in the water potential of the cells in that tissuc, meaning that either cell turgor or cell osmotic potential must decline. For most tissues, the decline is most apparent in cell turgor, and since many important plant processes, such as expansive growth and stomatal opening, are believed to be turgor dependent, it is expected that overall plant growth should be reduced as plant water deficits become more severe. Hence, it has been somewhat surprising that measurements of plant water potential have not been widely used for irrigation scheduling in crop plants. Factors that have probably contributed to this lack of use have been the high degree of variability reported for leaf water potential under field conditions (c.g., Smart and Barrs, 1973) and reports that, in some cases, leaf water potential responded in a manner oppo-

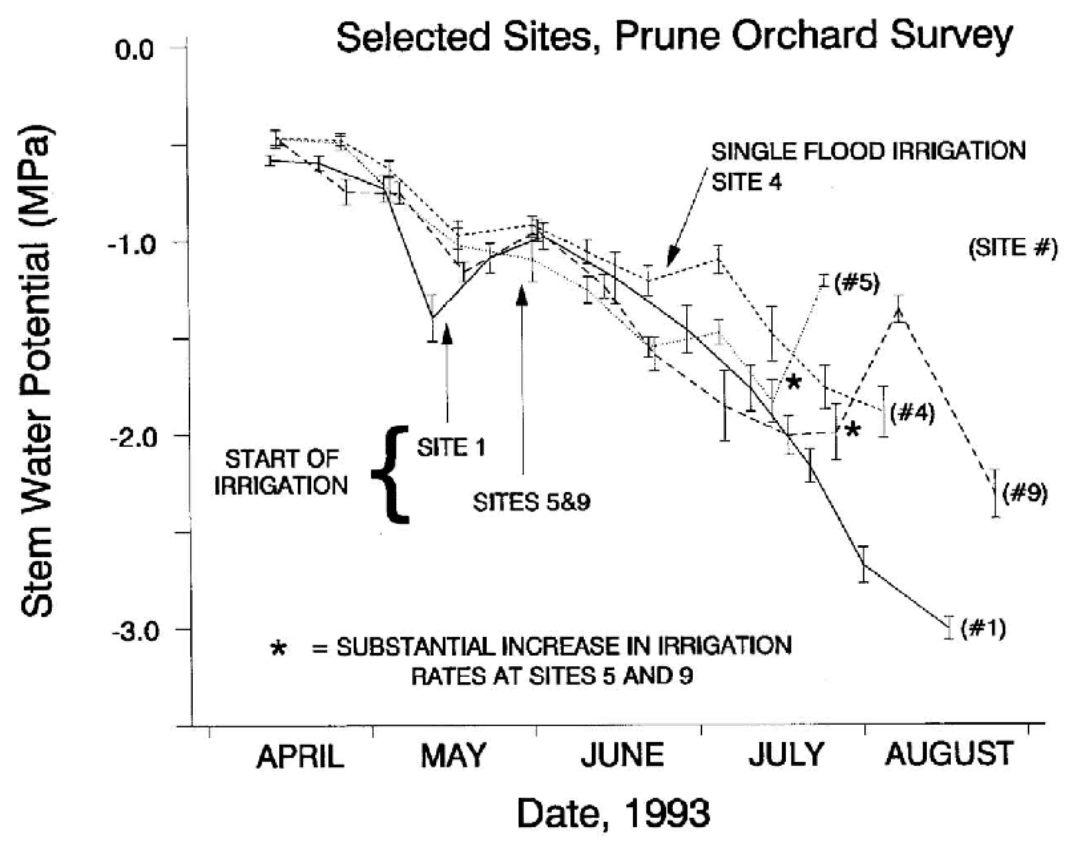

site to that expected, based on the irrigation treatments applied (Jones et al., 1983). It is important to note that essentially all of these studies have used the water potential of an outer-canopy, well-exposed, transpiring leaf as a measure of plant water potential.

It is commonly assumed that any consistent method of sampling and measuring plant water potential will accurately reflect real differences in plant water status if they exist. In peach trees however, Garnier and Berger (1985) found that during most of the day, stem water potential (i.e., the water potential of an attached leaf that has been prevented from transpiring by enclosure in a darkened plastic bag) was consistently related to irrigation treatment differences, whereas transpiring leaf water potential was not. This observation was particularly important, because stem water potential indicated that there was a difference between wet and dry treatment trees, whereas leaf water potential indicated that there was not. Hence, using the same technique (i.e., the pressure chamber) to measure leaves that were sampled from the same plants at the same time of day gave qualitatively different results depending on whether or not the leaf in question was transpiring at the time of sampling. The reasons for this difference are not yet clear, but since leaf transpiration has been associated with substantial within-leaf gradients in water potential (Shackel and Brinckmann, 1985) it is possible that a lowering of the water potential at one point in the transpiring leaf (c.g., near the leaf xylem) may not be detected as any change in average leaf water potential. This would be the case, for instance, if an $0.1 \mathrm{MPa}$ decrease in leaf xylem water potential led to stomatal closure, reduced transpiration, and an $0.2 \mathrm{MPa}$ decrease in the within-leaf water potential gradient. Assuming average leaf water potential represents a point half way through the within-leaf gradient, this 0.2 MPa decrease in the gradient would cause an increase of $0.1 \mathrm{MPa}$ in the average, exactly compensating for the $0.1 \mathrm{MPa}$ decrease experienced in the leaf xylem water potential.

The results of Garnier and Berger (1985) suggest that midday stem water potential may be an accurate index of plant water status, and, hence, be of use in irrigation scheduling and plant water relations studies. Midday stem water potential in prune reflected irrigation treatment effects and was

Fig. 1. Mean midday stem water potential during the 1993 growing season at selected sites in the prune orchard survey (Table 1), annotated to indicate notable irrigation events. Error bars indicate $\pm 2 \mathrm{sE}$, which, for the sample size $(N=10)$, is about a $95 \%$ confidence limit. 
Fig. 2. Relationship of midday stem water potential to midday vapor-pressure deficit (VPD) for June, July, and August in all of the sites indicated in Table 1. Each point represents a single measurement on an individual tree, and points are in vertical files corresponding to the midday VPD at each orchard on the date of measurement. Also shown is the relation found by McCutchan and Shackel (1992) for well irrigated trees in Davis, Calif.

also found to be well related to water use at the leaf and the canopy level (McCutchan and Shackel, 1992). There was also evidence in this study that stem water potential was more sensitive than transpiring leaf water potential as an indicator of the progressive drying that followed each irrigation event during the growing season. This paper demonstrates the utility of midday stem water potential as a physiological index of plant water status and as a guide for irrigation practices in deciduous fruit trees.

\section{Results and discussion}

McCutchan and Shackel (1992) found that midday stem water potential for continuously irrigated prune trees ranged from -0.5 to $-1.0 \mathrm{MPa}$ over the season, depending on the midday vapor-pressure deficit (VPD), whereas, for trees that were not irrigated, the values progressively declined over 3 months to about -3.0 MPa. When these latter trees were irrigated, their midday stem water potentials rapidly recovered to that of the continuously irrigated controls. In 1993, a survey was conducted in several mature prune orchards in California chosen to include a wide range of soil conditions and irrigation system types (Table 1). For many of these sites, midday stem water potentials were similar to the control levels reported in McCutchan and Shackel (1992) during the early portion of the growing season, but later in the season declined to as low as $-3.0 \mathrm{MPa}$ (Fig. 1), suggesting that many of these trees were under irrigated. In essentially all cases, irrigation events were associated with an increase in midday stem water potential, but very few growers maintained their orchards in the

Fig. 3. Seasonal pattern of mean midday stem water potential for almond trees under three irrigation regimes in Winters, Calif. Error bars indicate \pm 2 $\mathrm{SF}$, which, for the sample size $(\mathrm{N}=8)$, is about a $95 \%$ confidence limit. Also shown is the water potential predicted from the midday vapor-pressure deficit (VPD) as found in prune by McCutchan and Shackel (1992).

Hortechnokogy • January-March $1997 \quad 7(1)$
All Sites, 1993 Prune Orchard Survey

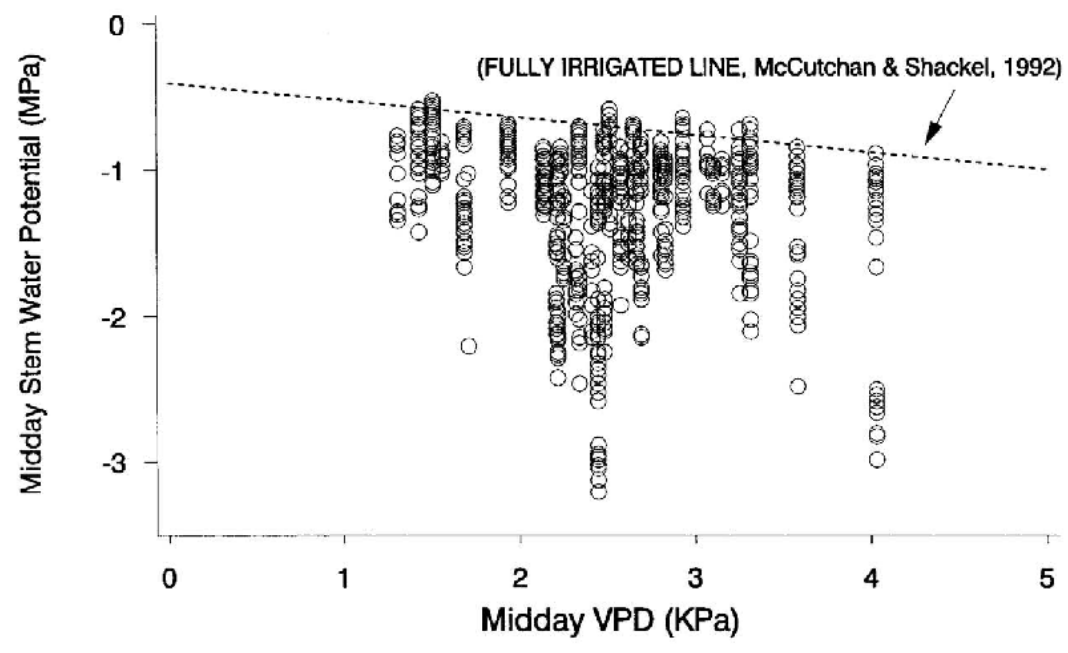

-0.5 to $-1.0 \mathrm{MPa}$ range during the entire season. To account for day-to-day and seasonal changes in evaporative demand, midday stem water potential of all individual trees was plotted as a function of midday VPD (Fig. 2). This analysis showed that the relationship found by McCutchan and Shackel (1992) for prune under high-frequency irrigation established an accurate upper limit for midday stem water potential, which could be applied to many different sites and irrigation regimes. Since all points that are substantially below this limit represent water potentials substantially less than expected, it appears that prune orchards may be routinely managed at some level of tree water stress, particularly late in the growing season. This suggests that growers have not recognized any deleterious production effects as a result of water stress and is consistent with evidence that moderate water stress may benefit prune

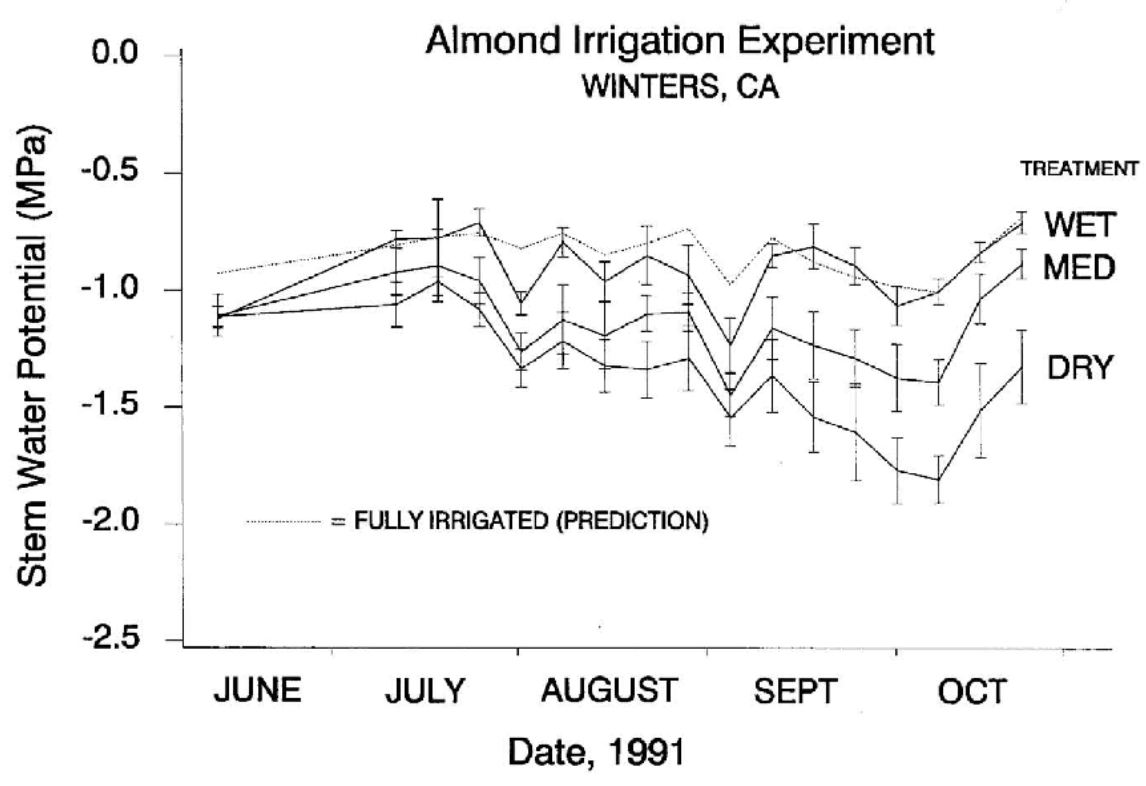




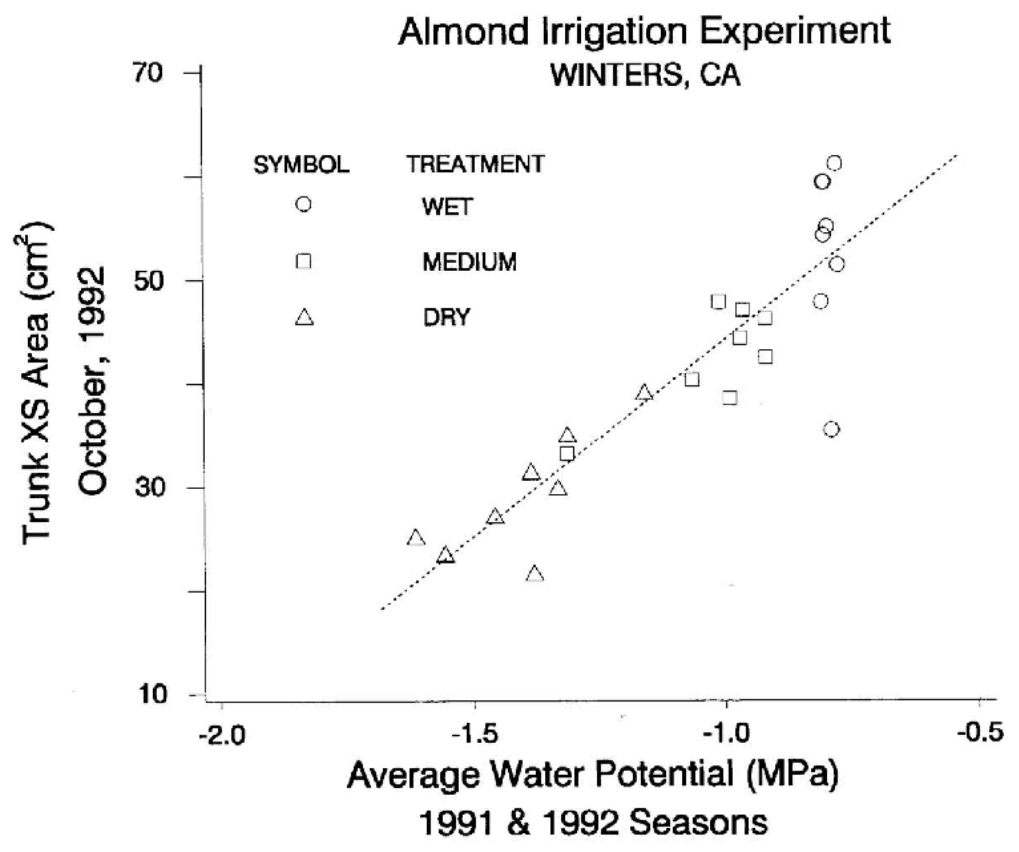

production (Lampinen et al., 1995). The aim of our current research is to determine the appropriate levels of stress for maintenance of long-term prune tree productivity.

Almond trees were planted in an experimental orchard in Winters, Calif, in February 1991, and grown under three contrasting irrigation regimes for 2 years. In 1991 for example, trees in the wet irrigation regime

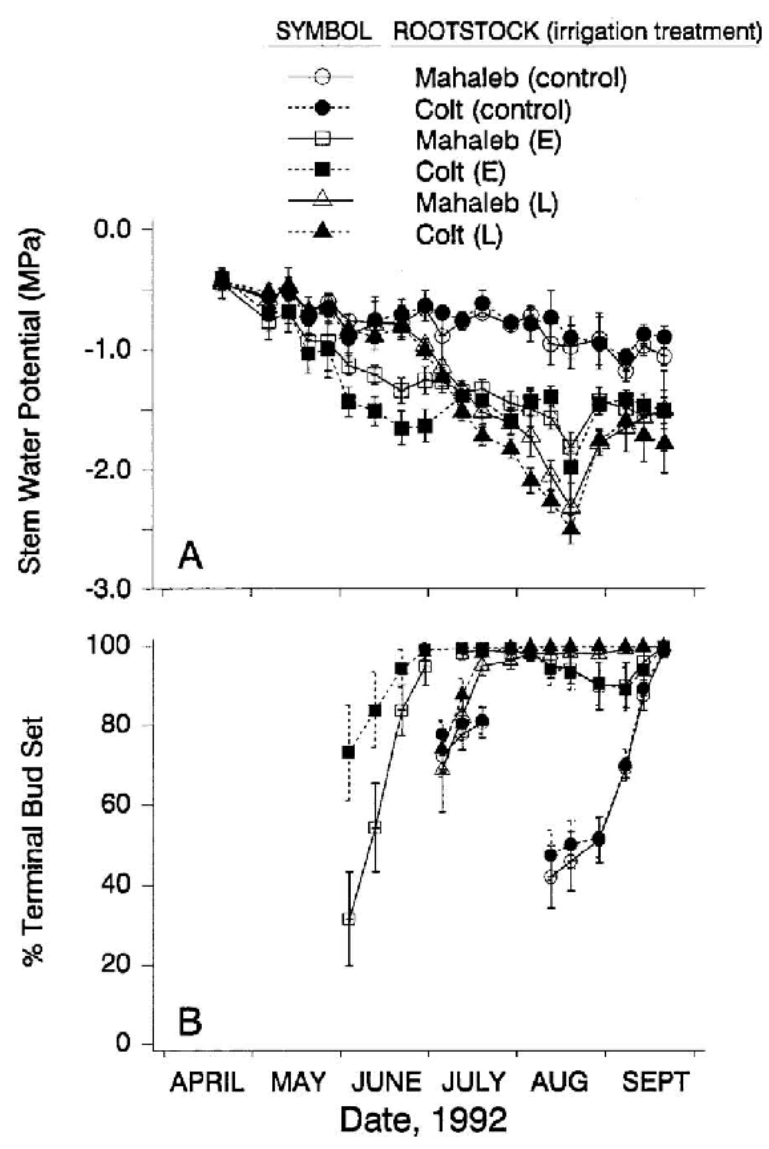

Fig. 4. Relationship between the trunk cross-sectional area after two seasons of growth and the average midday stem water potential over the same two seasons for 24 individual almond trees under the same three irrigation regimes as shown in Fig. 3. Also shown is the regression line for these data $\left(R^{2}=0.78, P<0.001\right)$.

received $900 \mathrm{~mm}$, trees in the medium regime received $300 \mathrm{~mm}$, and trees in the dry regime received $50 \mathrm{~mm}$ of applied water. Irrigation was applied with a highly uniform microsprinkler irrigation system that was operated twice weekly in the wet and medium treatments and monthly in the dry treatment. Based on the midsummer measurements of shaded ground area, a previously published relationship of shaded area to crop coefficient in almond (Ferreres and Goldhamer, 1990), and the cumulative reference crop evapotranspiration for this area in 1991 [California Irrigation Management and Information System (CIMIS) $\mathrm{ET}_{0}$ ], seasonal crop water demand was estimated at $\approx 300 \mathrm{~mm}$. Hence, the two extreme treatments represented substantial over and under irrigation. Midday stem water potentials were identical in the three treatments before the irrigation season and clearly reflected treatment differences once irrigation was commenced (Fig. 3). Also, the values of midday stem water potential exhibited by the almond trees in the wet irrigation regime were essentially identical to those found by McCutchan and Shackel (1992) in continuously irrigated prune trees, except during August. Interestingly, during August the almond trees under the wet irrigation regime were being irrigated at about double the predicted crop water demand. After observing, however, that the midday stem water potentials were slightly lower than might be expected (i.e., reaching -1.2 $\mathrm{MPa}$ on 4 Sept.), the rate of irrigation was increased on 5 Sept. to four times the predicted crop water demand, resulting in a small but consistent increase in midday stem

Fig. 5. Seasonal pattern of (A) midday stem water potential and $(B)$ percentage of the nongrowing (i.e., set) terminal buds, for young 'Bing' sweet cherry trees grafted on either 'Mahaleb' (solid lines, open symbols) or 'Colt' (dashed lines, closed symbols) rootstock under well-irrigated conditions during the season (control, circles), or irrigation deprivation early ( $E$, squares), or late ( $L$, triangles) in the growing season. The reduction in the terminal bud set in the control treatment between July and August was associated with a summer pruning treatment. Error bars indicate \pm 2 sE, which, for the sample size $(\mathrm{N}=8)$, is about a $95 \%$ confidence limit. 
Fig. 6. Relationship between the bud growth (as a percent of control) and the corresponding midday stem water potentials during July and August for the rootstock and irrigation treatments shown in Fig. 5.

water potential after this date. Substantial differences in tree canopy size were apparent by the end of the first growing season (data not shown), and, based on trunk cross-sectional area as a measure of overall tree growth, there was a strong linear relationship between tree growth and average tree midday stem water potential by the end of the second growing season (Fig. 4). This relationship is particularly interesting because it demonstrates that the tree-to-tree variation within each treatment in midday stem water potential (i.e., the error bars. in Fig. 3) reflected real differences in tree water status, which, over time, were also apparent as differences in individual tree growth. Another interesting characteristic of Figs. 3 and 4 is the indication that tree-to-tree variation in midday stem water potential is minimized under very wet soil conditions and increases as soil conditions become drier. This can be seen is Fig. 3 as smaller error bars in the wet compared to the medium or dry treatments, especially after $\mathbf{5}$ Sept., and in Fig. 4 as a narrower range of $x$-axis values for the wet compared to the medium or dry treatments. This observation may indicate that as soils become drier, the availability of water to individual trees may be influenced as much by spatial variability in the soil as it is by the imposed irrigation treatments themselves. Hence, even though there was a clear irrigation treatment effect on midday stem water potential, and despite the very large differences in the amount of water applied to the different irrigation treatments, there were some trees in the dry treatment that exhibited midday stem water potentials and overall rates of growth that were similar to, or better than, some trees in the medium treatment. A similar result was found in a pear tree irrigation experiment (sec below). These results stress the importance of using a plant-based

Fig. 7. Relationship between mean fruit size and mean midsummer midday stem water potential for individual pear trees under three irrigation regimes in Ukiah, Calif. Treatment means for the average fruit size are also shown (inset). Each point represents a single tree, and the line shown is a smoothed spline through all the points. The linear regression for these points was significant at $P<0.001\left(R^{2}=0.55\right)$.

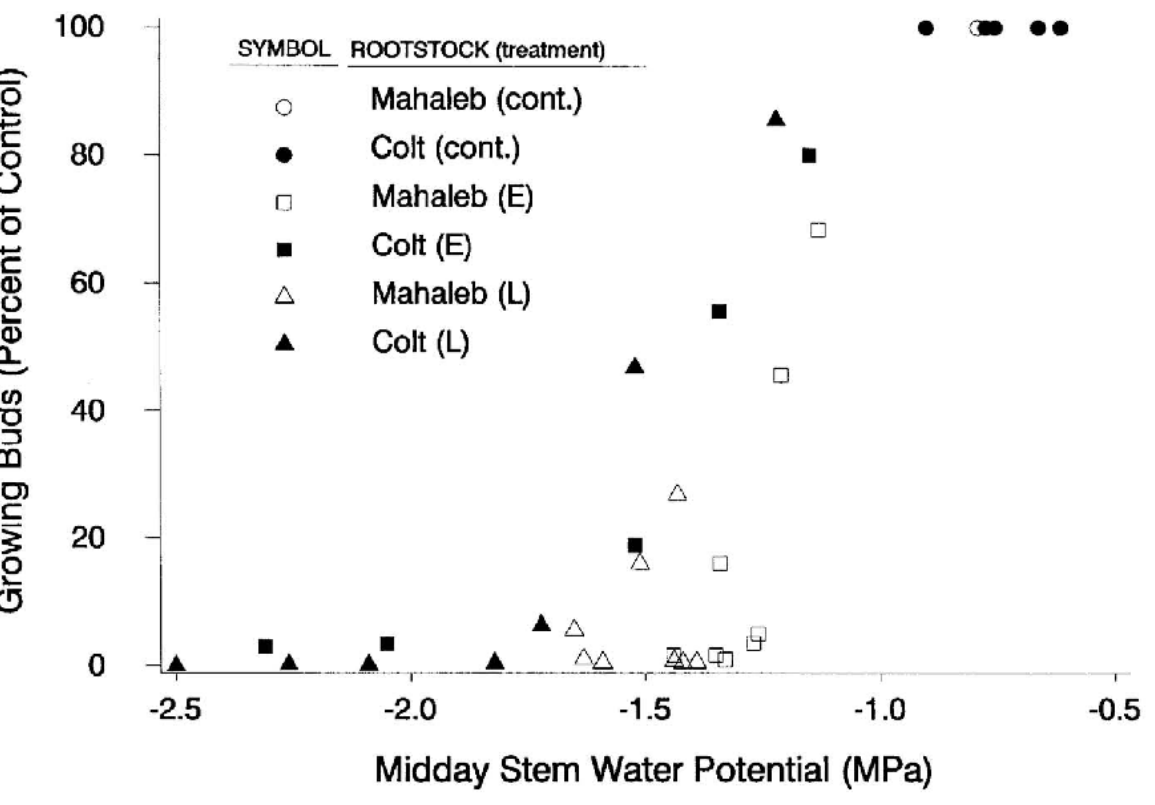

measure of water status to help interpret results obtained from irrigation experiments, particularly to quantify the effectiveness of the treatments themselves.

Regulated deficit irrigation (RDI) has been proposed as a means of reducing excessive tree vegetative growth (e.g., Chalmers et al., 1984), and a combined rootstock-irrigation experiment was conducted in Winters, Calif., to determine the feasibility of this approach to manage young 'Bing' cherry tree growth and development. Three irrigation treatments (fully irrigated control, or water deprivation beginning early or late in the growing season ) were applied to young cherry trees grafted on 'Mahaleb' (Prunus mahaleb L.), a seed propagated rootstock, and 'Colt' (P. avium $\times$ P. pseudocerasus), a vegetatively

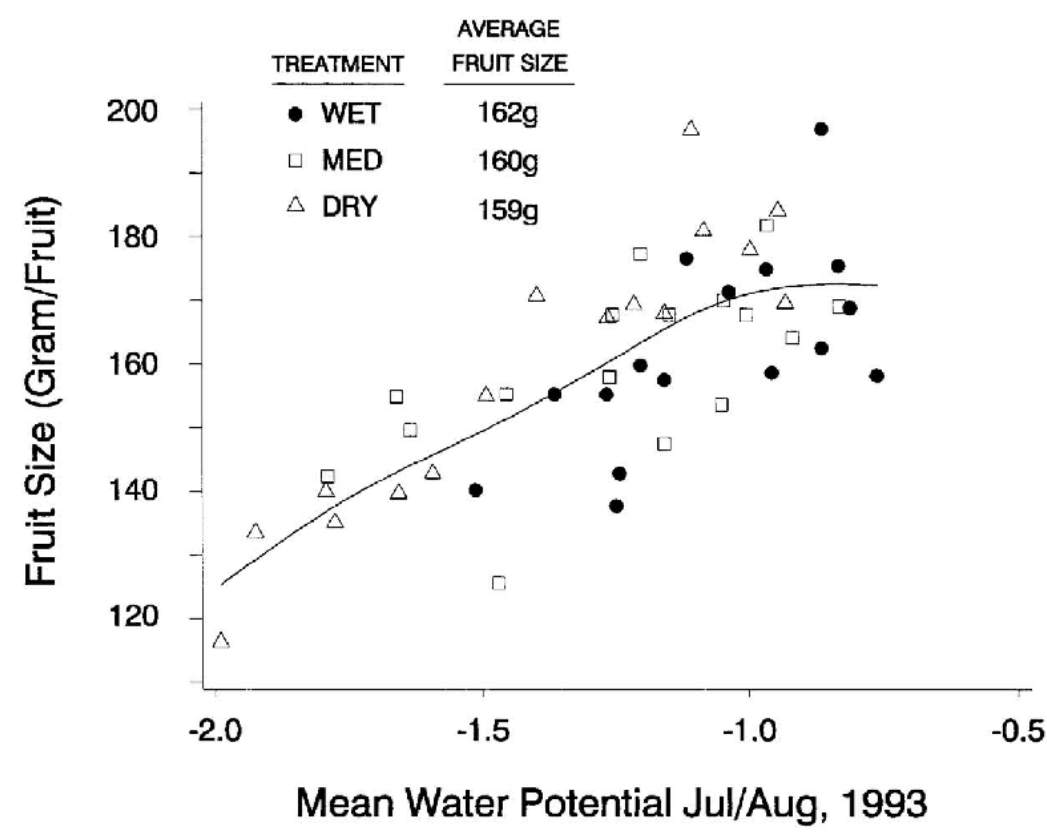


propagated rootstock. No rootstock effect on midday stem water potential was apparent under fully irrigated conditions, but, at both times in the season when irrigation was reduced, trees on the 'Colt' rootstock exhibited a more rapid decline in water status than trees on the 'Mahaleb' rootstock (Fig. 5A) and also showed a more rapid increase in the percentage of buds that had terminated growth (Fig. 5B). Some variation in bud growth occurred in the control trees during July as a result of summer pruning. Summarizing the data by expressing the number of growing buds in each treatment-rootstock combination as a percent of their respective control values, however, demonstrated that most of the rootstock effect could be accounted for by rootstock differences in midday stem water potential, with both rootstocks showing a similar decline in bud growth over the water potential range of -1.2 to -1.5 $\mathrm{MPa}$ (Fig. 6). The earlier reductions in stem water potential and bud growth with the 'Colt' rootstock compared to the 'Mahaleb' rootstock may indicate a difference in effective rooting depth between these rootstocks and is consistent with the commonly held view that vegetatively propagated rootstocks establish a more spreading, shallower root system than seed propagated rootstocks. From the relationship shown in Fig. 6, it appears that trees on 'Mahaleb' rootstock may actually be more sensitive to reductions in plant water status than those on 'Colt' rootstock, with a $50 \%$ growth reduction occurring at around $-1.2 \mathrm{MPa}$ in 'Mahaleb' compared to around $-1.5 \mathrm{MPa}$ in 'Colt'. Figure 6 also indicates that a smaller but similar shift in the growth-water potential relation may have occurred during the season, with similar growth reductions at slightly higher values of water potential early in the season than later in the season for both rootstocks. A close relationship between midday stomatal conductance and midday stem water potential was also found (data not shown), and this relation was identical for trees on the two rootstocks. As in the almond experiment, these data indicate a strong relationship between water status and tree vegetative growth, and further indicate that for some fruit trees the appropriate irrigation management practice to limit vegetative growth may depend on rootstock.

Midday stem water potential was not only related to vegetative growth, but was also closely related to fruit growth in pear. During the 1992-94 growing seasons, an irrigation experiment was performed in a mature pear orchard in Ukiah, Calif., in which water approximating $100 \%, 85 \%$, and $65 \%$ of the seasonal orchard water demand was applied by solid-set sprinklers to the wet, me- dium, and dry treatments, respectively. As was found in prune and almond, irrigation deprivation caused reductions in midday stem water potential, but in these pear trees the tree-to tree variation within each treatment was substantially greater than the variation between treatments. Thus, there was a small, nonsignificant irrigation treatment influence on average fruit size in 1993 (inset, Fig. 7), but when the data were analyzed on an individual tree basis, a strong relationship between average fruit size and average midday stem water potential was apparent (Fig. 7). Similar relations to midday stem water potential were found for tree vegetative growth based on pruning weights (data not shown). In addition to fruit size, other important fruit quality factors were related to stem water potential, for instance fruit soluble solids content and yellow color increased linearly with decreasing average midday stem water potential (data not shown). Hence, under these conditions, localized soil or tree factors appear to have a dominant influence on tree water status and ultimate fruit size, despite a fairly wide range of irrigation amounts.

\section{Conclusions}

Under all of the field conditions studied, decreases in midday stem water potential were closely associated with reductions in vegetative and reproductive growth and also reductions in other physiological attributes such as stomatal conductance. These responses are all typical of plant adaptive responses to water limited conditions. Under frequently irrigated conditions, many different fruit tree species appear to exhibit a similar range of midday stem water potential: from -0.5 to 1.0 MPa, depending on midday VPD. Hence, midday stem water potential can be used to reliably quantify stress and may serve as a useful guide for making irrigation decisions on a site-specific basis. It should not be assumed, however, that irrigation need will always be indicated when values of midday stem water potential are below their maximum value, since there is evidence that mild to moderate water stress may not reduce horticultural productivity, and in some crops may actually have beneficial effects.

\section{Literature cited}

Canny, M.J. 1995. A new theory for the ascent of sap-Cohesion supported by tissue pressure. Ann. Bot. 75:343-357.

Chalmers, D.J., P.D. Mitchell, and P.H. Jerie (1984). The physiology of growth control of peach and pear trees using reduced irrigation. Acta Hort. 146:143-149.

Ferreres, E. and D.A. Goldhamer (1990). Deciduous fruit and nut trees. In: B.A. Stewart and D.R. 
Nielsen (eds.). Irrigation of agricultural crops. Agron. Ser. 30. Madison, Wis.

Garnier, E. and A. Berger. 1985. Testing water potential in peach trees as an indicator of water stress. J. Hort. Sci. 60:47-56

Jones, H.G., M.T. Luton, K.H. Higgs, and P.J.C. Hamer. 1983. Experimental control of water status in an apple orchard. J. Hort. Sci. 58:301-316.

Kramer, P.J. 1983 Water relations of plants. Academic Press, New York.

Lampinen, B.D., K.A. Shackel, S.M. Southwick, B. Olson, J.T. Yeager, and D. Goldhamer. 1995. Sensitivity of yield and fruit quality of French prune to water deprivation at different fruit growth stages. J. Amer. Soc. Hort. Sci. 120:139-147.

McCutchan, H. and K.A. Shackel. 1992. Stem water potential as a sensitive indicator of water stress in prune trees (Prunus domestica L. cv. French). J. Amer. Soc. Hort. Sci. 117:607-611.

Shackel, K.A. and E. Brinckmann. 1985. In situ measurement of epidermal cell turgor, leaf water potential, and gas exchange in Tradescantia virginiana L. Plant Physiol. 78:66-70.

Smart, R.E. and H.D. Barrs. 1973. The effect of environment and irrigation interval on leaf water potential of four horticultural species. Agr. Meteorol. 12:337-346.

\section{You Can Win the Game!}

\section{New from ASHS Press...}

The first book written to assist green industry professionals in marketing organics and compost-related products and services. This one-of-a-kind publication is must reading for anyone interested in learning more about the rapidly expanding - and profitable organics market.

\section{Featuring}

The Compost Factory Paradigm

Retail Markets... The Highest Value for Compost?

An Overview of the Green Industry Markets

Sports Turf Markets for Compost

- Landscapers...The Leading Market for Compost

- Popular Uses for Compost in Nurseries

Marketing Compost Through Topsoil Blenders

- Silviculture, Roadside, and Reclamation Markets for Compost

- Agricultural Markets for Compost

Emerging Specialty Markets for Compos

- The Economic Angle of the Compost Business

The TEMPS Plan for Marketing Compost -Sales Management for Compost Marketers

- The Use of Training as a Way to Counter Competition

\section{ASHS Press}

American Society for Horticultural Science 600 Cameron Street, Alexandria, VA 22314-2562

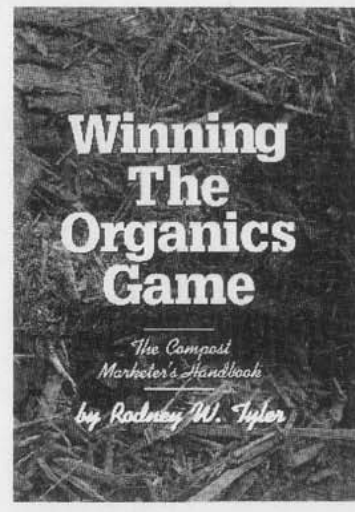

\section{A Special Offer from ASHS Press to ASHS} Members...

List Price:

$\$ 59.95$

ASHS Member price:

Offer available only to ASHS Members. (Additional discounts available for bulk orders...call 703.836.2418 for details!)
Yes! I want to order __ copies of "Winning the Organics Game_-The Compost Marketer's Handbook" at the special ASHS Member price of $\$ 48.00$ per copy.

Name:

Address: City: Country: State: ZIP/Postal Code:

| Payment Method: Phone: Fax:

Shipping/handling: U.S - \$4; Canada/Mexico\$6; International Air-\$20; Surface \$7.00 Virginia residents add $4.5 \%$ sales tax Check

(Make payable in U.S. funds to ASHS Press) American Express $\square$ VISA Mastercard

No. @ \$48.00 each Shipping/Handling Total Amount Enclosed

Name on card

Card Number Expiration Date

Authorized Signature

Return this form with payment to: ASHS Press, Dept. L, 600 Cameron Street, Alexandria, VA 22314 2562. Or, phone in your order today to ASHS Press at 703.836.2418, or fax to 703.836.6838 